\title{
De Moscovici a Jung: el arquetipo femenino y su iconografía
}

\section{From Moscovici to Jung: the feminine archetype and its iconography}

\author{
Jesús Saiz Galdós; Beatriz Fernández Ruiz; José Luis Álvaro Estramiana \\ Universidad Complutense \\ jesus_saiz@hotmail.com
}

\section{Resumen}

Nuestras representaciones de la mujer hunden sus raíces en los mitos del pasado. De acuerdo con Jung, los mitos son la expresión del inconsciente colectivo, el cual se manifiesta a través de los arquetipos. Los arquetipos son imágenes que pasan de una generación a otra, instrumentos del pensamiento colectivo. Los arquetipos principales tratados en este artículo son el de la Madre y el del Ánima o principio femenino del hombre. La posibilidad de analizar las representaciones iconográficas de la mujer desde la perspectiva de los arquetipos de Jung supone incluir la noción de inconsciente colectivo en el análisis de sus representaciones modernas. Mientras que la teoría de las representaciones sociales de Moscovici nos ofrece la posibilidad de analizar las creencias acerca de la mujer a lo largo de la historia, la perspectiva junguiana nos revela la posibilidad de analizar los mitos sobre la mujer como parte de los arquetipos con los que damos sentido a la realidad.

Palabras clave: arquetipo, inconsciente colectivo, representación social

\section{Abstract}

Our representations of women have their origins in the myths of the past. According to Jung, myths are the symbolic expression of the collective unconscious that expresses itself through archetypes. Archetypes are thus images that pass across generations: instruments of collective thought. The main archetypes we deal with in this article are the Mother and the Anima, or men's feminine principle. Using Jung's concept of archetype to analyse women's iconographic representations allows us to combine the notion of the collective unconscious with that of social representations. Whereas Moscovici's theory of social representations offers us the possibility of analysing beliefs about women through history, Jung's perspective reveals us the possibility of analysing the myths constructed around women as part of the archetypes people use to give sense to reality.

Keywords: archetype, collective unconscious, social representations

\section{Introducción}

Este estudio tiene como objetivo general tratar el tema propuesto por Álvaro y Fernández (2006) en su artículo dedicado a explorar las representaciones sociales de la mujer desde la teoría elaborada por el psicólogo social Serge Moscovici. Volver a analizar un mismo tema pero desde una perspectiva diferente incluye supuestos que, aunque de forma breve, es preciso señalar. Si desde una concepción clásica del positivismo o desde el positivismo lógico, nuestros enunciados deben 
corresponderse con una realidad externa, agotando la explicación causal del fenómeno observado, la irrupción de una nueva forma de explicación del mismo objeto de estudio, desde este paradigma epistemológico, sólo es posible desde el supuesto del avance científico. De esta forma, la anterior comprensión del objeto de estudio quedaría superada por una nueva comprensión más ajustada a un conocimiento científico. Ciertamente, nuestro punto de arranque para este artículo no es dicha concepción (neo)positivista, sino una muy alejada de la misma en la que se asume, además de la inconmensurabilidad de las teorías (Kuhn, 1962/75), el perspectivismo orteguiano (1916/1983) y la concepción contextualista del conocimiento de McGuire (1983). Así, resulta imposible comparar la teoría de las representaciones sociales de Moscovici (1961/79) con la teoría de los arquetipos de Jung (1934). Ambas obedecen a lógicas diferentes, pues a través de los conceptos que manejan y de la trabazón de los mismos, comprendemos la realidad observada desde estructuras conceptuales y metódicas que no son comparables entre sí. Por otro lado, entre el objetivismo del positivismo y el subjetivismo del relativismo cabe una noción de la realidad como sustrato real de nuestras ideas, cogniciones, representaciones, etc., pero también como construcción. Así, el perspectivismo no niega la realidad ni afirma que ésta sea una mera construcción de nuestros sentidos o nuestra interacción simbólica, sino que la realidad es multiforme y, por tanto, puede ser analizada desde perspectivas complementarias. Finalmente, el contextualismo de McGuire, parte de la idea de que las teorías no se contraponen necesariamente y que dependiendo del objeto de estudio, nos explican una parte de la variabilidad de la información que recogen. Todas estas observaciones que sirven como antecedentes epistemológicos de este trabajo, también son compatibles con las tesis más moderadas de la subdeterminación de las teorías por los hechos. No se trata de postular aquí que siempre es posible o deseable mostrar una teoría que corrige o anula una teoría previa, sino que en ciencias sociales es factible pensar en términos de nuevas teorías que, sin agotar la comprensión del objeto de estudio, incluyan postulados que sean plausibles desde el punto de vista de la comprensión del objeto de estudio y estén enunciados en términos que hagan posible la discusión argumentada de los mismos. De esta manera, utilizando el mismo material empírico que emplearon Álvaro y Fernández (2006), realizaremos una (re)lectura de éste desde otro referente teórico, que nos permita arrojar luz sobre aspectos no tratados en el estudio anterior. Así, entendemos que las teorías son instrumentos de interpretación de la realidad, y no principios universales que encuentran su validación en una comprobación empírica en la que la pertinencia de una teoría excluye la validez de otra.

El análisis de la presencia de la mujer como imagen colectiva puede realizarse con gran detalle desde un punto de vista psicodinámico. Conocer las vías en que ha sido representada la mujer a lo largo de la historia, y las funciones psicosociales que estas imágenes femeninas han desempeñado en el individuo y los grupos, obliga a tomar en cuenta la noción junguiana de los arquetipos. Así, este estudio empleará el concepto de arquetipo para explicar las variadas formas en que la mujer ha sido representada. Para esto, se analizarán distintas representaciones iconográficas de lo femenino que, como obras de arte, han podido plasmar a la mujer en diferentes momentos y dimensiones. Estas representaciones iconográficas han sido obtenidas de la "Ciudad de la Pintura" (http://pintura.aut.org/), con excepción de las marcadas con asterisco, que provienen del artículo de Álvaro y Fernández (2006).

El uso de términos y conceptos junguianos en este contexto hará además justicia al recordar a un autor clásico en la literatura psicológica, cuya pertinencia en Psicología Social y Psicología Social de las Organizaciones ya fue destacada por otros autores (Munné, 1996; Downs, Durant y Eastman, 2002). Finalmente, para Jung (1954a, 1954b) la mujer ha sido representada por dos tipos de arquetipos: el arquetipo de la madre y del ánima. 


\section{Marco teórico: El inconsciente colectivo y el arquetipo}

Tratar el concepto del inconsciente colectivo de Jung exige revisar antes las aportaciones pioneras de Freud y Durkheim.

En primer lugar, fue Freud (1900) quien desarrolló la noción del "inconsciente". Para este autor la personalidad del individuo tenía una dimensión consciente y una más amplia inconsciente (además de una intermedia a la que denominó preconsciente). Sin embargo, el inconsciente para Freud poseía la particularidad de ser personal, es decir, los contenidos que incluía podían ser tanto actos latentes y temporalmente inconscientes (deseos, intenciones, etc.), como procesos personales reprimidos. En este sentido, Jung realizó una gran contribución a las ciencias sociales, al proponer una dimensión interpersonal o colectiva que ampliaba el concepto del inconsciente propuesto por Freud.

En segundo lugar, cabe atribuirle a Durkheim (1912, p. 14) el desarrollo de la noción de "representación colectiva". Para este autor, "las representaciones colectivas son el producto de una inmensa cooperación extendida no sólo en el tiempo, sino también en el espacio; una multitud de espíritus diferentes han asociado, mezclado, combinado sus ideas y sentimientos para elaborarlas; amplias series de generaciones han acumulado en ellas su saber. Se concentra en ellas un capital intelectual muy particular, infinitamente más rico y complejo que el individual". Estas representaciones colectivas deben entenderse como categorías que trascienden el ser individual para recoger una serie de ideas esenciales, como el tiempo, el espacio, la causalidad, la cantidad, etc., que de no ser homogéneas harían imposible la vida común. Las representaciones colectivas de Durkheim constituirían el conjunto de conocimientos que gobiernan la vida social del sujeto, pero que se diferenciarían del inconsciente colectivo junguiano, precisamente, en su calidad de información consciente.

En este sentido, la noción del "inconsciente colectivo" de Jung recogería elementos tanto del inconsciente freudiano como de las representaciones colectivas de Durkheim. Así, a diferencia de Freud (1900), quien subrayaba el carácter personal del inconsciente, y a diferencia de Durkheim (1912) que propuso la existencia de una instancia colectiva, pero perteneciente a la conciencia, Jung (1936) hizo especial hincapié en otra dimensión general, que siendo inconsciente para el sujeto, se extendía a todos los individuos. A esta instancia la denominó inconsciente colectivo y representa el conjunto de elementos sociales y culturales en los que el sujeto está inmerso y no es consciente de ellos. Además, el inconsciente colectivo incluiría tanto contenidos del folklore y las costumbres, como actitudes, valores, creencias y disposiciones religiosas.

Dentro de este inconsciente colectivo, Jung (1936) situó los "arquetipos". Éstos fueron definidos como ideas o formas preconcebidas que actuaban sobre los individuos determinando sus acciones y comportamientos. En este sentido, el arquetipo (Jung, 1941, p. 150): “... no sólo presenta algo que ha sido y que ha pasado hace tiempo sino también algo actual, es decir, no es sólo un residuo sino un sistema que sigue funcionando hoy y que está destinado a compensar o a corregir adecuadamente los inevitables unilateralismos y extravagancias de la conciencia".

La forma en que Jung (1941) consideró que se activaban los arquetipos era, precisamente, obedeciendo dos principios clave en su teoría: la compensación y el equilibrio de los opuestos. El primero lo emplea para referirse a la acción homeostática del inconsciente, el cual, a semejanza del cuerpo humano, busca un equilibrio siempre en la psique del sujeto. Por ejemplo, según Jung, una persona sumamente introvertida puede buscar compensación inconsciente en sus sueños al verse 
como alguien extrovertido. En este sentido, el equilibrio de los opuestos es un principio que Jung deriva de la compensación, y que implica polaridades y dicotomías en cada aspecto de la personalidad. De esta manera, ambos principios explican la razón por la cual se manifiestan unos arquetipos y no otros, es decir, la manifestación de los arquetipos está en función de las necesidades personales y la situación psicosocial del sujeto. Una vez más, la función de los arquetipos es compensatoria.

Además, aunque aquí nos centraremos únicamente en dos arquetipos (el de la madre y el ánima), será necesario reconocer que para este autor (Jung, 1936, p. 47): "hay tantos arquetipos como situaciones típicas en la vida. Una repetición interminable ha grabado esas experiencias en nuestra constitución psíquica...". Ejemplos de otros arquetipos comunes serían el del héroe, el niño, el sabio, el padre, Dios, etc.

Por otra parte, cabe reconocer que la noción de arquetipo puede ser considerada un importante antecedente al "símbolo" de Durand (1968), entendido como formas de acción a través de las cuales el sujeto interactúa e interpreta el mundo social y personal. Otro concepto que, desde la biología, está sumamente relacionado con el arquetipo, en cuando patrones o guías inconscientes colectivas del comportamiento, son los "campos mórficos" de Sheldrake (1990).

En resumen, los arquetipos representan contenidos del inconsciente colectivo, que determinan multitud de comportamientos y acciones. Éstos, acumulados en la memoria histórica del género humano, están impregnados de matices tan variados como la religión, la mitología, los valores, las costumbres y las creencias. Finalmente, su forma de activación obedece al principio de compensación, es decir, los arquetipos residen en el inconsciente colectivo, pero sólo se activan en los sujetos en virtud de su situación psicosocial.

También debemos tomar en cuenta que fueron Freud y Jung los principales autores que dieron al origen del mito una interpretación psicológica. En La interpretación de los sueños, Freud (1900) reconoció una afinidad en la función de los mitos y los sueños. Ambos juegan un papel en la vida de la mente inconsciente. Incluso llegó a relacionar los símbolos de los mitos con los de los sueños. De la misma manera, Jung consideró que los mitos y los sueños pueden revelar configuraciones de la mente inconsciente. Pero buscó sus raíces en el inconsciente colectivo, planteando la existencia de una relación continua y heredada de la humanidad con ciertos símbolos clave.

En los mitos encontramos las tendencias psíquicas normativas de una sociedad. Sus contenidos expresan las necesidades inconscientes y los miedos o conflictos de las sociedades antiguas y modernas. Y esa forma de expresión antigua y tradicional contribuye al equilibrio psíquico y social del grupo (Kirk, 1974).

Pero la idea misma de "arquetipo" sigue siendo lo más cuestionable en la visión de Jung. Es discutible que la disposición a formar determinados símbolos (como la madre tierra, el niño divino, el sol, dios, la idea femenina del hombre -o ánima- y la idea masculina de la mujer -o ánimus-) sea universal y recurrente en diversas tradiciones mitológicas.

Ciertamente, la teoría de Jung sobre los arquetipos adolece de una formulación de carácter psicosociológico sobre la transmisión de los mismos. En su opinión no son ni aprendidos ni conscientes, lo que les sitúa en el ámbito hereditario o instintivo dificultando su utilización como parte de un proceso de construcción histórica y cultural. Pese a esta crítica, nada impide formular su existencia como parte del devenir histórico de la humanidad, de los procesos de socialización que se 
dan en cada cultura y, finalmente, de los procesos de interacción social y desarrollo de la psique. Desde esta perspectiva es desde la que adoptamos las nociones de inconsciente colectivo y arquetipo, una vez despojadas de sus atributos innatos o hereditarios. Queda abierta la cuestión sobre si sería posible hacer compatibles la teoría de los arquetipos de Jung y la teoría de las representaciones sociales de Moscovici (1961/79; 1984, 1998). Ambas parten de teorías diferentes; el psicoanálisis, por un lado, el cognitivismo y cierta adscripción al construccionismo por otro. Sin embargo, mientras a la teoría de Moscovici le falta una comprensión antropológica e histórica del papel del mito en la construcción de las representaciones e identidades sociales contemporáneas, en la teoría de Jung está ausente un análisis de los mecanismos psicosociales de construcción de los arquetipos. Dicho análisis es el que elabora Moscovici de una forma clara y que tiene una gran utilidad analítica y hermenéutica al señalar que las representaciones sociales son construcciones del conocimiento de sentido común que tienen sus raíces en los procesos de anclaje y objetivación. Moscovici nos da así unas herramientas conceptuales con las que vincular la psique individual con los procesos sociales de construcción de sentido de la realidad. La teoría de Jung se instala en un vacío social, cultural e histórico pues no hace explícitos los mecanismos a través de los cuales los arquetipos se construyen a lo largo de la historia como procesos culturales que se interiorizan en la mente de los individuos, siendo éstos quienes transforman en el curso de las interacciones cotidianas su sentido y validez para aprehender el mundo. Realizadas estas matizaciones, sólo cabe afirmar que la utilización de la teoría junguiana en el contexto de este artículo no tiene como objetivo la validación de dicha teoría -algo, por otra parte imposible dadas las premisas de las que parte-, sino su utilización como herramienta analítica de construcciones sociales que derivan su contenido de la existencia de los mitos; en este caso de la mitología femenina con la que a lo largo de la historia se han construido las imágenes de la mujer.

\section{Análisis iconográfico: La mujer como arquetipo}

Los dos principales arquetipos femeninos que Jung (1954a, 1954b) reconoce son: el arquetipo de la madre y el ánima. No obstante, y dados los principios de compensación y equilibrio de los opuestos arriba mencionados, para conocer el arquetipo de la madre, habrá que explorar tanto sus connotaciones positivas como negativas y para explicar el arquetipo del ánima, habrá que hacer referencia también al arquetipo del ánimus.

\section{Arquetipo de la Madre}

Según Jung, como arquetipo, la imagen de la madre trasciende el plano personal para llegar a uno más colectivo. En este sentido, la madre no es sólo esa persona física que nos dio a luz, sino que igualmente, nuestra experiencia de la madre está determinada por un conjunto de valores, actitudes, roles y expectativas que obedecen a un arquetipo, firmemente arraigado en la tradición sociocultural. Motivos de expresión del arquetipo de la madre abundan en la mitología y las religiones (María en el cristianismo, Parvati en el hinduismo, Deméter en la mitología griega, Isis en el Egipto antiguo, etc.), lo cual implica que el arquetipo de la madre posee varias dimensiones. Algunas podrían ser positivas, como por ejemplo todo lo asociado con la protección y fertilidad; y otras serán negativas, como la muerte, el poder destructivo de la madre naturaleza o simplemente "lo desconocido". 
Nos ayuda a entender el arquetipo de la madre el pensar que la madre humana se explicó en las primeras formas religiosas como imagen de la tierra fértil, que es a la vez la creadora y el lugar de origen, y la tumba; ambos aspectos se unen en el ciclo de la vida (Eliade, 1976, 1981). El enterramiento en vasijas en el mundo antiguo tiene este simbolismo, las cenizas del difunto vuelven a un recipiente que simboliza el útero materno, donde esperar un nuevo renacimiento más allá de la muerte (Neumann, 1955; Crawford, 1957).

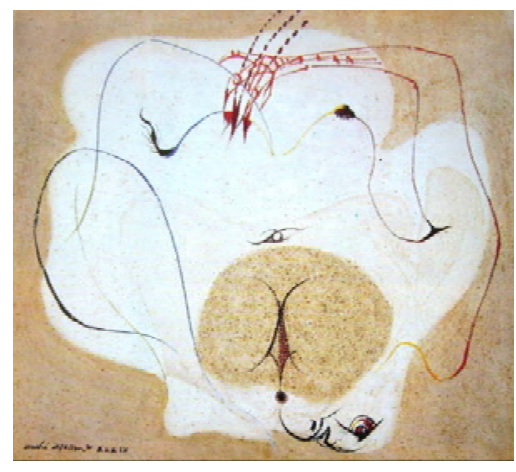

Fig. 1. La Tierra

El cuadro La tierra, de André Masson (1939), presenta un cuerpo femenino en escorzo, mostrando en primer término el sexo. El color es el de la arena pegada al lienzo, tierra y cuerpo femenino reproductor se unen. Los artistas surrealistas habían buscado en los mitos y en el estudio de la mentalidad primitiva una alternativa a la visión racional. Unieron la lectura de Freud -La interpretación de los sueños (1900), Tótem y tabú (1913)- con el interés por los estudiosos de las formas elementales de la conciencia humana: Frazer, La rama dorada (1911-14); Lévy-Bruhl, Las funciones mentales en las sociedades inferiores (1910), La mentalidad primitiva (1922). La fe en el poder creativo del inconsciente se une en los surrealistas a la convicción de la importancia del sueño en la vida humana, y a la aceptación de la necesidad universal del mito (Maurer, 1994).

Las cuatro categorías que Jung (1954b) definió para el arquetipo de la madre son:

\section{Autoridad, sabiduría y altura espiritual más allá del intelecto.}

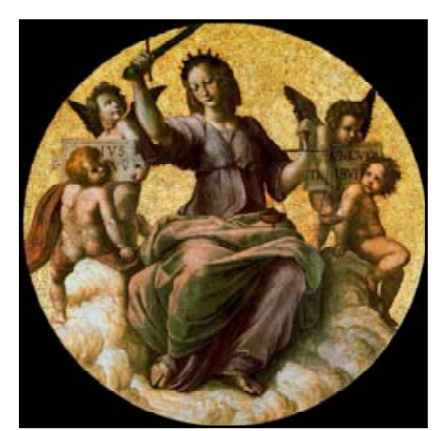

Figura 2. La Justicia

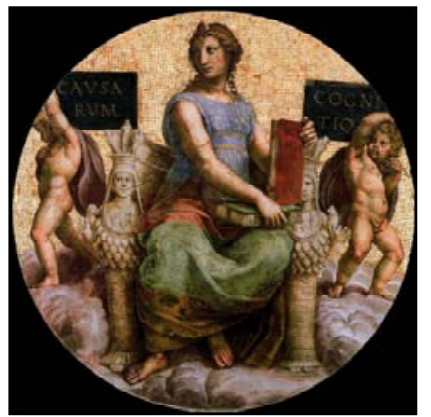

Figura 3. La Filosofía

Un sentido totalmente positivo del arquetipo de la madre lo expresan aquellas representaciones alegóricas que identifican a la mujer con atributos como La Justicia o La Filosofía, por ejemplo, en los 
frescos de Rafael (1508-1511) en las Estancias del Papa en el Vaticano. Además, la mujer ha poseído en diferentes tradiciones una importante autoridad religiosa. Un ejemplo de este aspecto del arquetipo son las sibilas griegas, que Miguel Angel (1508-1512) pintó en la Capilla Sixtina del Vaticano, contraponiendo estas adivinadoras paganas a los profetas del Antiguo Testamento; o la Coronación de la Virgen pintada por el Greco (1591-1592).

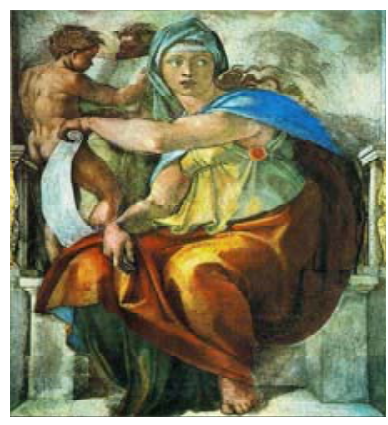

Fig. 4. Sibila Délfica

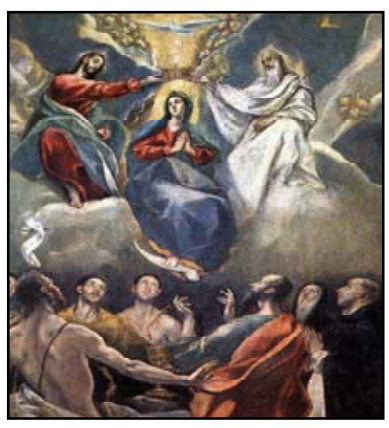

Fig. 5. Coronación de la Virgen

\section{Lo bondadoso, protector, sustentador, lo que da crecimiento, fertilidad y alimento (lo maternal).}

Identificar a la mujer con la fertilidad, la reproducción y la protección constituye un segundo aspecto del arquetipo de la mujer realmente típico. En este sentido las imágenes de la Mujer Ovípara (Lychosthenes, 1557) y la Musa amamantando (Lavater, s.a.) representan exageraciones de estos valores, en donde se transmite una idea de la función protectora, cuidadora y maternal de la mujer.

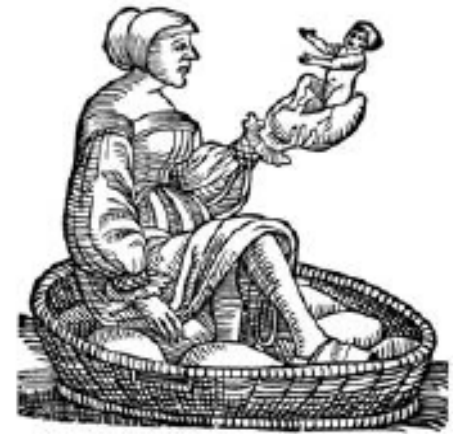

Figura 6: Mujer Ovípara

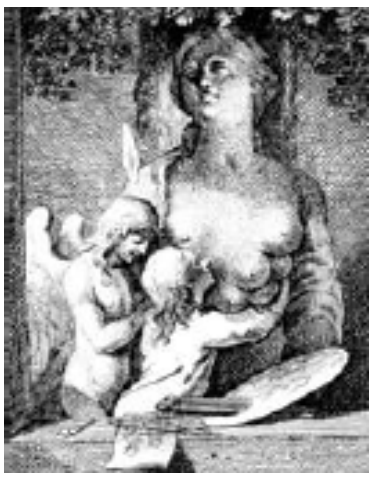

Figura 7. Musa amamantando

\section{Lugar de la transformación mágica, del renacer; el instinto o impulso que ayuda.}

Según la mitología griega, cada vez que Perséfone sale del reino de Hades hacia la Tierra, encontrándose con su madre Deméter (Diosa de la Tierra), se inicia la primavera, y cuando regresa al infierno comienza el invierno. Este renacer y transformación mágica que ocurre tras la unión madrehija, se representada en la pintura El Regreso de Perséfone (Giordano, 1634-1705), que muestra las características de transformación y renacer de la naturaleza expresadas en el arquetipo de la madre (Jung, 1941b). Además, la representación de la mujer haciendo énfasis en atributos emocionales e 
instintivos de ayuda, es un aspecto que se ve bien reflejado en la imagen anónima (s.a.) que muestra la adopción por una loba de Rómulo y Remo, en el origen mitológico de Roma.

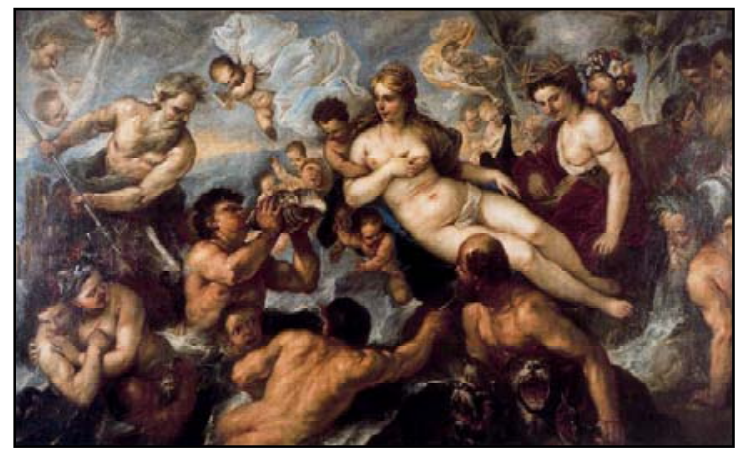

Fig. 8. El Regreso de Perséfone

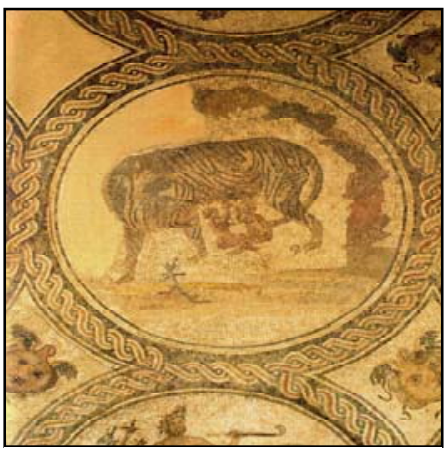

Fig. 9. Mosaico de la loba

4. Lo secreto, escondido, tenebroso, el abismo, el mundo de los muertos, lo que devora, seduce y envenena, lo angustioso e inevitable.

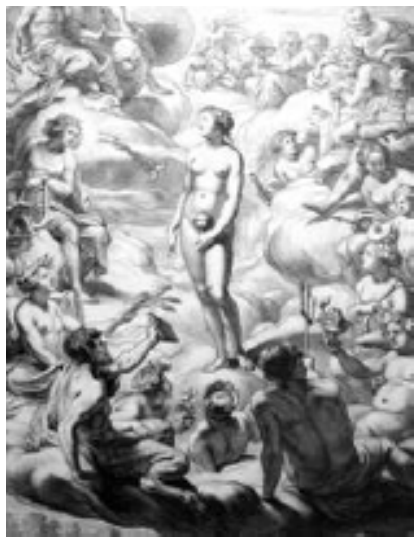

Figura 10. La caja de Pandora*

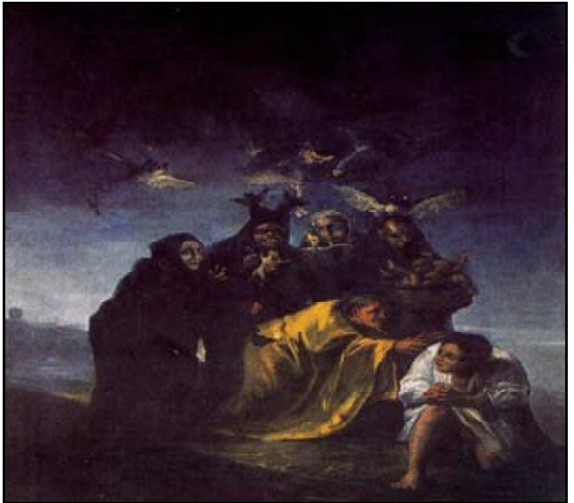

Figura 11. Escena de Brujas

Finalmente, en una sociedad dominada por hombres, no resulta extraño encontrar el aspecto más tenebroso del arquetipo sobreactivado. El poder destructivo de la naturaleza, lo inesperado de la misma, lo desconocido y misterioso, son también cualidades del arquetipo de la madre. La imagen de Pandora (Marolles, 1655) que trae consigo la caja con las desgracias a los hombres -aunque también contenga la esperanza- es sumamente significativa. La Escena de brujas de Goya (1798) muestra también ese aspecto de la mujer mayor, aliada de lo oculto, que seduce, tienta y daña al inocente.

\section{Arquetipo Ánima}

En la teoría junguiana el ánima representa la parte femenina del varón mientras que el ánimus es la parte masculina de la mujer. Para Jung, tan importante era que el hombre aceptase su feminidad como la mujer su masculinidad. De esta manera, este autor propuso la existencia de un arquetipo que 
compensase los elementos conscientes asociados con la identidad de género (masculino y femenino).

En síntesis, las nociones de ánimus y ánima hacen referencia al elemento masculino que se encuentra en la mujer (ánimus), y al elemento femenino que se encuentra en el hombre (ánima). Dado que el objetivo de este estudio es examinar la forma arquetípica en que la mujer o la feminidad se ha expresado a lo largo de la historia, aquí nos centraremos exclusivamente en el ánima, alejándonos del arquetipo del ánimus. En este sentido, cabe decir que el ánima junguiana obedece a los mismos principios que todos los arquetipos, es decir, pertenece al inconsciente colectivo y aparece en escena por compensación.

Así, para este autor, (Jung, 1964, p. 471): "Todo hombre lleva la imagen de la mujer desde siempre en sí, no la imagen de esta mujer determinada, sino de una mujer indeterminada. Esta imagen es, en el fondo, un patrimonio inconsciente, que proviene de los tiempos primitivos y, grabada en el sistema vivo, constituye un tipo de todas las experiencias de la serie de antepasados de naturaleza femenina, un sedimento de todas las impresiones de mujeres, un sistema de adaptación psíquica heredado".

Finalmente, cabe destacar la gran influencia e importancia que este arquetipo (ánima) posee en el varón. Según Jung (1954a, p. 69) el ánima opera, principalmente, sobre las emociones y afectos, otorgando virtudes y rasgos que son socialmente asociados a la mujer. Así, tomando en cuenta los principios de equilibrio entre los opuestos y compensación, Jung (1941b) describió tres grandes categorías dicotómicas en las que se podría expresar el ánima.

\section{Vieja versus Joven}

Una primera forma de representar este arquetipo femenino es como una mujer vieja versus una mujer joven. De esta manera (Jung, 1941, p.186): "el hombre infantil suele tener una figura de ánima maternal; uno maduro, en cambio, una figura femenina más joven. Pero el «demasiado viejo» está compensado por una muchacha muy joven, incluso por una niña". Aquí se exponen algunas representaciones pictóricas de la mujer, como vieja (Vieja Usurera, Ribera, 1638; Cabeza de una vieja campesina con cofia blanca, Van Gogh, 1885) y como joven (Retrato de una joven, Borndone, 1540-1560; Joven vestida de rosa, Camille de Corot, 1796-1875; Thérèse de Balthus, 1938).

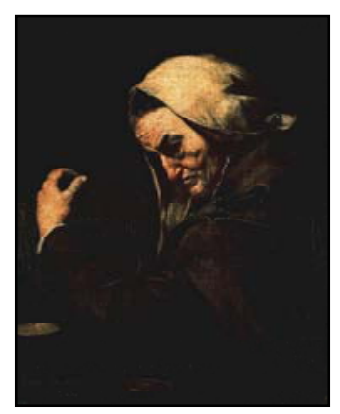

Figura 12. Vieja Usurera

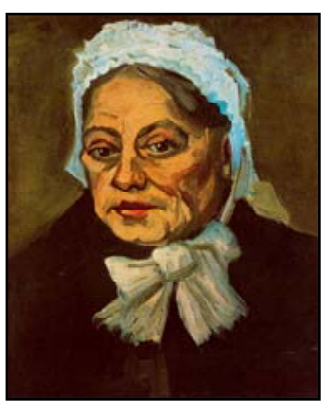

Figura 13. Cabeza de vieja campesina con cofia

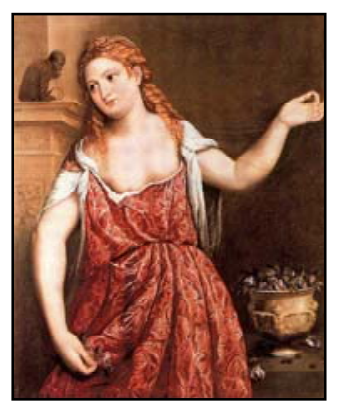

Figura 14. Retrato de una joven

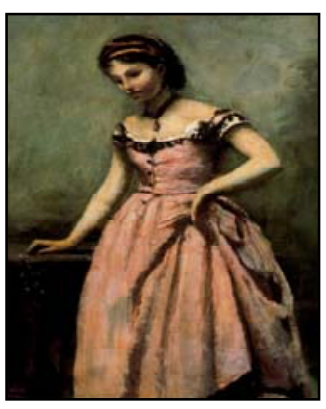

Figura 15. Joven vestida de rosa

A este respecto, resulta igualmente interesante recordar a las mujeres tahitianas que pinta Gauguin $(1893,1899)$, las cuales representan a la nativa sensual de un país joven y de naturaleza exuberante, en el que el hombre europeo, procedente de una civilización gastada, agotada, sueña con 
"reabastecerse". Él es la encarnación de lo viejo, de una civilización cansada, ella es como una fruta o una flor, la vida misma (Harrison, 1998, pp. 32-34).

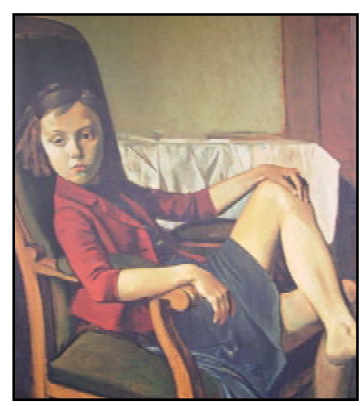

Figura 16. Thérèse

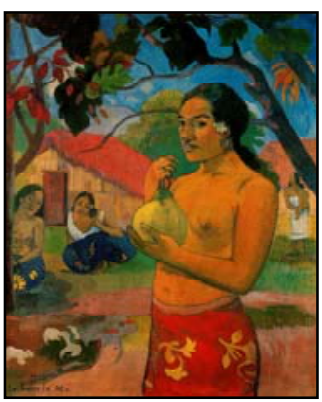

Figura 17. Mujer

sosteniendo una fruta

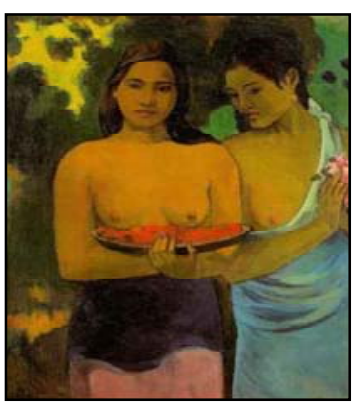

Fig. 18. Mujeres tahitianas con flores de mango

Muy en línea con ciertas interpretaciones junguianas sobre Gauguin se ha escrito que (Varnedoe, 1994, p. 187): "identificó primitivismo con auto-realización, no sólo porque pensara que la gente primitiva creara o concibiera en formas que él envidiaba, sino en un nivel aún más básico: porque creía que un movimiento hacia atrás o más allá de las tradiciones artísticas y las formas de vida occidentales le llevaría reflexivamente de vuelta hacia el interior de su propia psique, y que una simplificación externa apropiada de su arte y de su vida resolvería sus confusiones íntimas, literalmente para dar forma a su identidad más profunda".

\section{Hada buena versus Bruja}

Según Jung (1941b, 186) "Una gran parte del miedo que inspira a los hombres el sexo femenino proviene de la proyección de la imagen del ánima". Así, la segunda categoría de este arquetipo muestra la polaridad entre el hada buena, o la mujer que otorga dones, y la bruja, o personaje malvado que los arrebata. Imágenes como la de la Mujer arpía y del Antipapa de Aldrovandi (1599, 1642), o la Mujer diablo (Butler, 1709) hacen referencia a este aspecto negativo de la representación de la mujer que produce temor en el hombre. No obstante, quizá la figura femenina más terrible imaginada en el mito sea la Medusa, con su cabellera de serpientes y su mirada que petrifica. Según la mitología griega, era una de las tres hermanas Gorgonas que habitaban en el confín occidental del mundo (Bonnefoy, 1981). La imagen de Caravaggio (1598) da buena cuenta del horror que transmite.

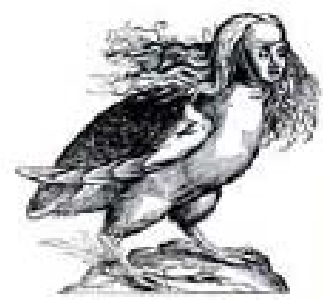

Figura 19. Mujer arpía

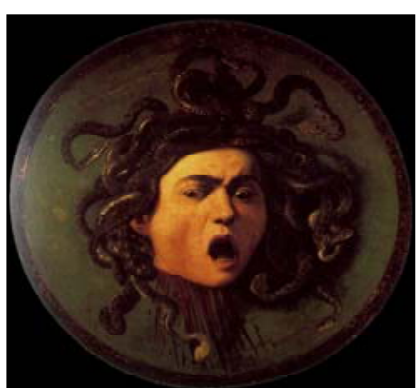

Figura 20. Cabeza de Medusa 


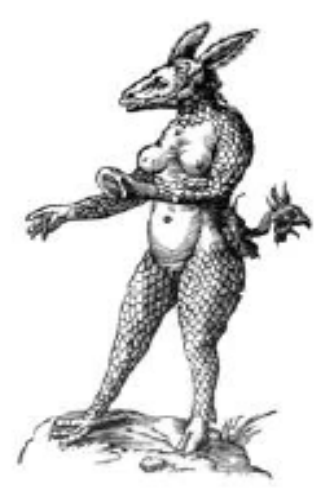

Figura 21. El Antipapa

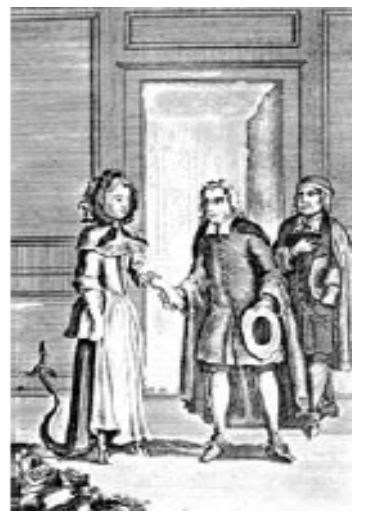

Fig. 22. Mujer diablo

Mientras que pinturas como la Diosa del buen consejo de Bayeu (1786) o la Abundancia de Brueghel (1568-1625) muestran ese otro aspecto benévolo y dadivoso del arquetipo femenino.

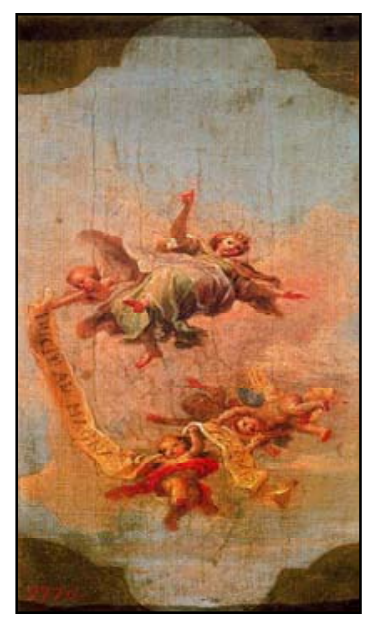

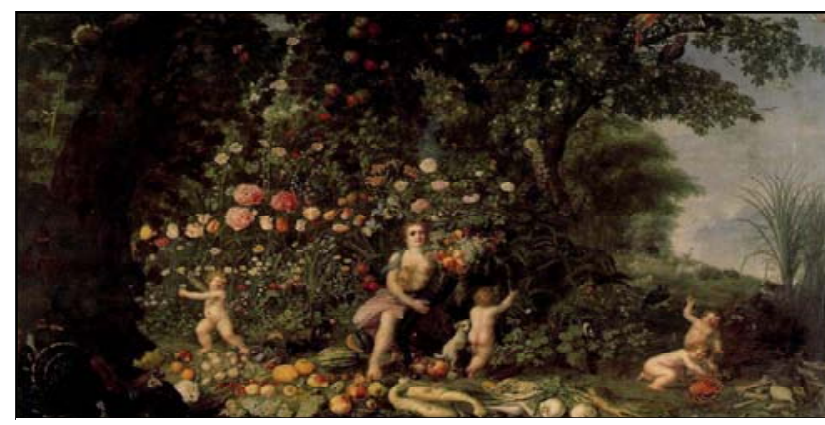

Figura 24. La Abundancia

Figura 23. Diosa del

buen consejo

Por otra parte, cabe subrayar que, tal y como sucede con el aspecto destructor y oscuro de la madre, el ánima, como bruja o figura femenina malvada, evidencia el miedo que una sociedad dominada por hombres ha depositado en la mujer. Así, la mujer ha sido objeto de proyección, en no pocos casos, del temor a lo desconocido, lo maligno, inesperado e incontrolado.

\section{Santa versus Seductora}

Finalmente, una última categoría para representar al ánima la constituye la de la mujer santa versus la mujer pecadora o seductora. Una imagen que plantea una dicotomía filosófica similar es el Amor sacro y Amor profano de Tiziano (1514-1515). 
En el siglo XVI, cuando Tiziano pintó este cuadro, la yuxtaposición de una mujer desnuda portando una llama (símbolo de la mente y también de la fe y la caridad cristiana) y una dama ricamente vestida, era aún considerada una antítesis entre los valores eternos y los temporales. El Amor sacro es la mujer desnuda, que simboliza la belleza universal y eterna. La mujer vestida encarna la belleza de la tierra, la de los hombres, los animales, las flores, los árboles, el oro y las obras creadas por el arte o la destreza. Cupido está colocado entre las dos mujeres, aunque algo más cerca de la belleza "natural" o "terrestre". Tiziano representa una armonía maravillosa entre la belleza interior y la visible. Ambas figuras simbolizan dos grados de perfección, no el contraste entre el bien y el mal.

El cuadro de Tiziano es un paisaje moral. También el fondo está dividido en dos partes: tras la mujer vestida vemos una ciudad fortificada y dos liebres, símbolos del amor animal y la fertilidad. El otro lado es un paisaje más rústico, pero más luminoso, con un rebaño de ovejas y una iglesia campestre.

Las dos mujeres se parecen mucho a la "Felicidad eterna" y la "Felicidad breve" explicadas por Cesare Ripa en la Iconología que publicó primero en Roma, en 1593, y después en Milán, en 1602. La felicidad eterna era una mujer rubia y joven de belleza deslumbrante. Su desnudez expresaba su desprecio a las cosas terrenas y perecederas. Una llama en su mano derecha simbolizaba el amor a Dios. La felicidad breve era una mujer con un vestido amarillo y blanco que significaba "satisfacción". Estaba adornada con piedras preciosas y sujetaba un vaso lleno de oro y gemas, símbolo de la dicha vana y pasajera (Panofsky, 1979, pp. 209-210).

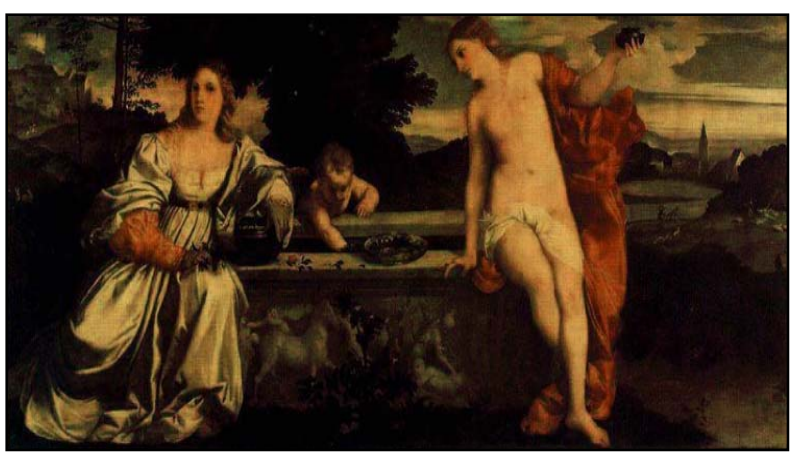

Figura 25. Amor sacro y Amor profano

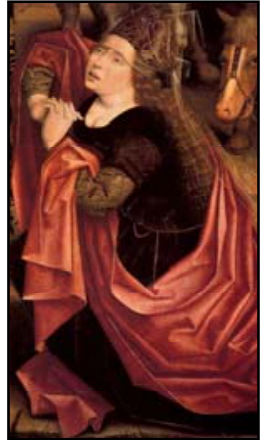

Fig. 26. Magdalena

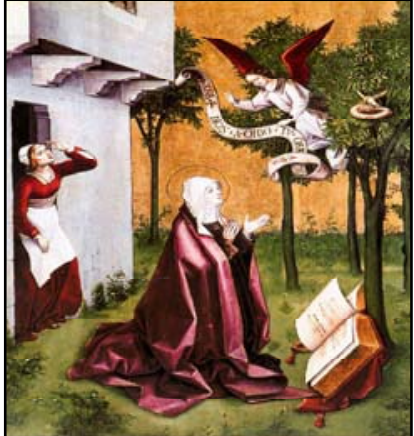

Fig. 27. Santa Ana

Así, a lo largo de la historia, se han realizado numerosas representaciones de mujeres santas (Magdalena de Baegert, 1477-1478; Anuncio del ángel a Santa Ana de Berruguete, 1450-1504; etc.). Como también, ha habido un gran número de imágenes de mujeres seductoras. Desde la famosa Eva ofreciendo la manzana a Adán (Tintoretto, 1550) hasta el Profano amor, la Vanidad de Tiziano (15141515) o la Mujer-Sensualidad (Anómino, s. XIX).

Por otra parte, cabe considerar que este aspecto del arquetipo, representando a la mujer como seductora, tiene mucho en común con el aspecto negativo de la dicotomía anterior. La mujer tentadora (por ejemplo, Eva) continúa siendo el chivo expiatorio en el que caen las culpas de las desgracias del hombre (ver también Pandora), visión que no podría ocurrir en otra sociedad distinta que la actual, dominada por el varón. 


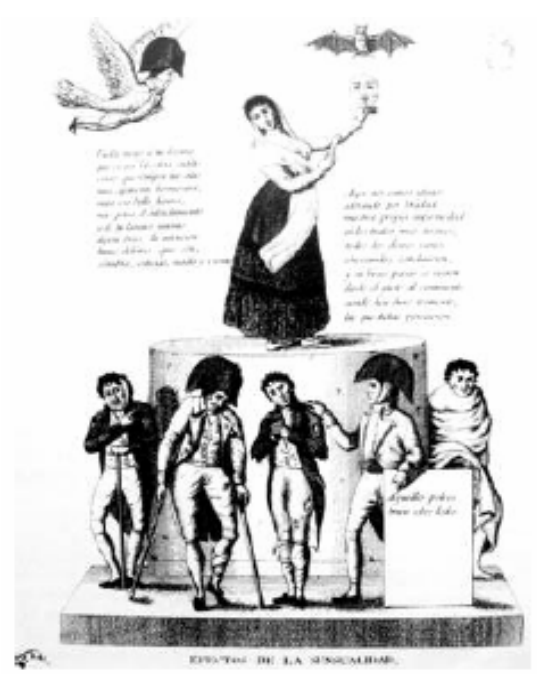

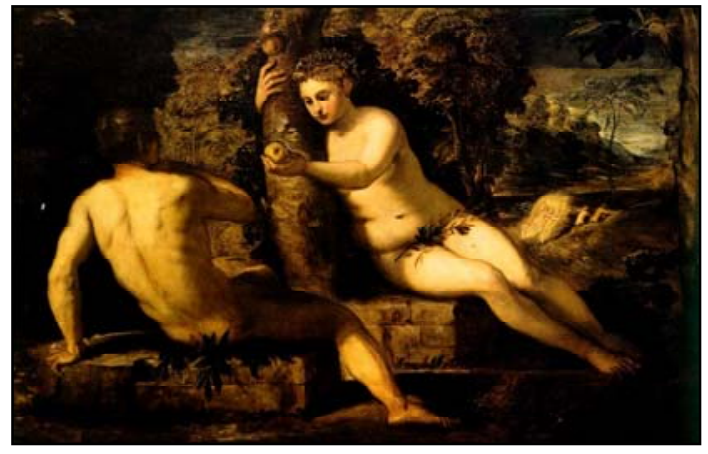

Figura. 29. Adán y Eva

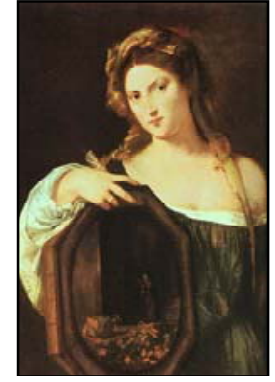

Fig. 30. Profano Amor, la Vanidad

Figura 28. Mujer-sensualidad

La noción de arquetipo nos permite reconocer la figura de la mujer en la psique colectiva del individuo. Ampliamos así la esfera de las representaciones sociales (Moscovici, 1961/79, 1984, 1998) a la dimensión inconsciente, para descubrir los temores, las virtudes, los defectos, los valores, etc. que ha producido en el individuo la imagen de la mujer como arquetipo a lo largo de la historia.

En este sentido, hemos podido reconocer dos arquetipos con características femeninas (la Madre y el Ánima), que a su vez engloban varias dimensiones de la mujer. Así, al revisar las representaciones iconográficas del arquetipo de la madre hemos podido descubrir valores y aspectos asociados a la madre dentro de un contexto sociocultural e histórico. Las dimensiones señaladas de este arquetipo son:

1. Autoridad, sabiduría y altura espiritual más allá del intelecto.

2. Lo bondadoso, protector, sustentador, lo que da crecimiento, fertilidad y alimento (lo maternal).

3. Lugar de la transformación mágica, del renacer; el instinto o impulso que ayuda.

4. Lo secreto, escondido, tenebroso, el abismo, el mundo de los muertos, lo que devora, seduce y envenena, lo angustioso e inevitable.

En estas dimensiones, figura una idea de la mujer que hace especialmente referencia a la autoridad y maternidad, además de comprender connotaciones instintivas, desconocidas y destructoras de la naturaleza.

Por otra parte, al analizar las representaciones iconográficas de lo femenino como ánima, se detallaron tres dimensiones dicotómicas:

1. Vieja versus Joven.

2. Hada buena versus Bruja.

3. Santa versus Seductora. 
Sobre la representación de la mujer como ánima cabe resaltar dos elementos. En primer lugar, el arquetipo de la mujer como vieja o joven hacía referencia a una compensación personal, en este caso del artista, que podía expresar su idea de mujer como joven o vieja en virtud de sus propias necesidades. En segundo lugar, el arquetipo del ánima, al corresponder al aspecto femenino del varón, mostró en repetidas ocasiones una importante cantidad de atributos negativos de la mujer (bruja, seductora, etc.). Esto apoyaría la hipótesis sostenida por Álvaro y Fernández (2006) de la representación social de la mujer como monstruo, en una sociedad dominada por hombres. En este sentido, la noción de ánima le confiere una cualidad particular, ya que expresa una dimensión inconsciente de la representación, para subrayar el papel del contexto sociocultural e histórico y de la proyección (de temores, represiones, etc.) en la configuración de esa imagen social de la mujer como criatura siniestra.

\section{Discusión}

Una de las teorías psicodinámicas clásicas de la personalidad, que más rica aplicación a la psicología social puede ofrecernos es, sin duda, la de C. G. Jung. Su concepto del inconsciente colectivo, que incluye el del arquetipo, aporta un sentido más profundo a la explicación del comportamiento del individuo en un contexto histórico-social. Así, trascendiendo las influencias de los instintos, Jung propone la existencia de un sustrato de la psique humana que comprende todos los contenidos, no conscientes, olvidados o reprimidos que caracterizan a la especie humana. Dentro de este inconsciente colectivo encontrará Jung los mitos y las religiones, diferentes formas tradicionales y aspectos culturales.

Las relaciones que el concepto de inconsciente colectivo puede mantener con el de representación social (Moscovici, 1961/79, 1984, 1998) son diversas. En primer lugar, de manera semejante, ambos conceptos definen un aspecto de la realidad social compartido. Es decir, trascienden la dimensión personal, para reflejar conjuntos de ideas, conocimientos e informaciones que son comunes a todos los sujetos. Sin embargo, las representaciones sociales, como lo demostraron en su estudio anterior Álvaro y Fernández (2006), arrojan luz sobre la forma en que un sociedad entiende y comunica algo. Así, las representaciones sociales de la mujer ponen el énfasis en una serie de valores y actitudes sociales formadas en una sociedad dominada por hombres, en la cual destacan los aspectos reproductivos y los monstruosos. No obstante, al aplicar la noción del inconsciente colectivo al análisis de las representaciones de la mujer, encontramos una serie de contenidos (arquetipos) que indican distintas facetas en las cuales la mujer ha sido y es representada a nivel inconsciente. Según Jung, la mujer no sólo es representada en el inconsciente colectivo según sus cualidades reproductivas y aspectos siniestros, sino que se deben reconocer también los aspectos de sabiduría, belleza y divinidad que ella encierra. Como señala Beauvior (1977, p. 185) la mitología construida entorno de la mujer revela el carácter contradictorio de su representación: "El mito es tan ondulante y contradictorio que en principio no se descubre su unidad...la mujer es Eva y la Virgen María al mismo tiempo. Es un ídolo, una sirvienta, la fuente de la vida, una potencia de las tinieblas, es el silencio elemental de la verdad, es artífice, charlatana y mentirosa; es la que cura y la bruja; es la presa del hombre, es su pérdida, es todo lo que él no es y quiere tener, su negación y su razón de ser".

Finalmente, dado que Jung solo establece categorías hipotético-descriptivas, resultaría ahora sumamente interesante la realización de un análisis más detallado en el que se pudiese determinar, qué representaciones de la mujer son, definitivamente, más predominantes en la sociedad actual. Las 
deficiencias de la teoría de Jung, señaladas en este artículo no son, como esperamos haber argumentado, óbice para hacernos eco de la capacidad analítica de sus conceptos. Nuestro interés no ha sido sino el de mostrar la posibilidad que nos abre la teoría psicoanalítica de Jung para el estudio e interpretación de las representaciones iconográficas de la mujer. Dichas representaciones no pueden obviar el estudio del mito en la formación e influencia que ejerce en las representaciones contemporáneas de la mujer, en nuestro conocimiento de sentido común cargado de reminiscencias mitológicas de carácter inconsciente.

\section{Referencias}

Álvaro, José Luis y Fernández, Beatriz. (2006). Representaciones sociales de la mujer. Athenea Digital, 9, 65-77. Disponible en http://antalya.uab.es/athenea/num9/alvaro.pdf

Beauvior, Simone de. (1977). El segundo sexo. Los hechos y los mitos. Buenos Aires: Siglo XX.

Bonnefoy, Yves. (1981/1996). Diccionario de las mitologías. Vol. II, Grecia, Barcelona: Destino.

Crawford, O.G.S. (1957). The Eye Goddess. Nueva York: MacMillan.

Downs, Alexis, Durant, Rita y Eastman, Ken. (2002). Introduction: Exploring the relevance of arquetypal psychology to organizational change. Journal of Organizational Change Management, 15, 5, 444-447.

Durand, Gilbert. (1968). La imaginación simbólica. Buenos Aires: Amorrortu.

Durkheim, Emile. (1912/1992). Las formas elementales de la vida religiosa. Madrid: Akal.

Eliade, Mircea. (1976/1999). Historia de las creencias y las ideas religiosas. Vol I. Barcelona: Paidós.

Eliade, Mircea. (1981). Tratado de historia de las religiones: morfología y dialéctica de lo sagrado. Madrid: Cristiandad.

Frazer, James George. (1922/1993). La rama dorada, México: Fondo de cultura económica.

Freud, Sigmund. (1900/1983). La interpretación de los sueños. Madrid: Biblioteca Nueva.

Freud, Sigmund. (1913/1999). Tótem y tabú. Madrid: Alianza.

Harrison, Charles, Frascina, Francis y Perry, Gil. (1998). Primitivismo, cubismo y abstracción. Los primeros años del siglo XX. Madrid: Akal.

Jung, Carl G. (1934). Sobre los arquetipos de lo inconsciente colectivo. En C. G. Jung. (2002). Los arquetipos y lo inconsciente colectivo. OC. 9. Barcelona: Trotta.

Jung, Carl. G. (1936). El concepto de inconsciente colectivo. En C. G. Jung. (2002). Los arquetipos y lo inconsciente colectivo. OC. 9. Barcelona: Trotta.

Jung, Carl. G. (1941a). Acerca de la psicología del arquetipo del niño. En C. G. Jung. (2002). Los arquetipos y lo inconsciente colectivo. OC. 9. Barcelona: Trotta.

Jung, Carl. G. (1941b). Acerca del aspecto psicológico de la Core. En C. G. Jung. (2002). Los arquetipos y lo inconsciente colectivo. OC. 9. Barcelona: Trotta. 
Jung, Carl. G. (1954a). Sobre el arquetipo con especial consideración del concepto del ánima. En C. G. Jung. (2002). Los arquetipos y lo inconsciente colectivo. OC. 9. Barcelona: Trotta.

Jung, Carl. G. (1954b). Los aspectos psicológicos del arquetipo de la madre. En C. G. Jung. (2002). Los arquetipos y lo inconsciente colectivo. OC. 9. Barcelona: Trotta.

Jung, Carl. G. (1964/2005). Recuerdos, sueños, pensamientos. Barcelona: Seix Barral.

Kirk, G.S. (1974/2002). La naturaleza de los mitos griegos. Barcelona: Paidós.

Kuhn, Thomas S. (1962). The structure of scientific revolutions. Chicago: University of Chicago Press. [Trad. La estructura de las revoluciones científicas. México: Fondo de Cultura Económica. 1975]

Lévy-Bruhl, Lucien (1910/1951) Les Fonctions mentales dans les sociétés inférieures. Paris: Les Presses Universitaires de France.

Lévy-Bruhl, Lucien. (1922/1966) Primitive Mentality. Boston: Beacon.

Maurer, Evan. (1994). Dada and Surrealism. En William Rubin (Ed.). "Primitivism" in 20th century art. Affinity of the Tribal and the Modern. Vol. II. Nueva York: The Museum of Modern Art.

McGuire, William. (1983). A contextualist theory of knowledge: Its implications for innovation and reform in social psychological research. En Leonard Berkowitz (Ed). Advances in experimental social psychology, vol. 16. Nueva York: Academic Press.

Moscovici, Serge. (1961). La psychanalyse, son image et son public. Paris : Presses Universitaires de France. [Trad. El psicoanálisis, su imagen y su público. Buenos Aires: Buemal. 1979]

Moscovici, Serge. (1984). The Phenomenon of Social Representations. En Robert Farr y Serge Moscovici (Eds). Social Representations. Cambridge: Cambridge University Press.

Moscovici, Serge. (1998). The history and actuality of social representations. En U. Flick (Ed). The psychology of the social. Cambridge: Cambridge University Press.

Munné, Frederic. (1996). Entre el individuo y la sociedad: marcos y teorías actuales sobre el comportamiento interpersonal. Barcelona: PPU.

Neumann, Erich. (1955). The Great Mother. Princeton: Princeton University Press.

Ortega y Gasset, José. (1916/1983). El espectador I. Obras Completas. Vol II. Madrid: Alianza.

Panofsky, Erwin. (1933/1979). Estudios sobre Iconología. Madrid: Alianza.

Sheldrake, Rupert. (1990). La presencia del pasado. Barcelona: Kairós.

Varnedoe, Kirk. (1994). Gauguin. En Rubin, William (Ed.). "Primitivism" in 20th century art. Affinity of the Tribal and the Modern. Vol. II. Nueva York: The Museum of Modern Art.

\section{Historia editorial}

Recibido: 20/12/2006 
Primera revisión: 20/03/2007

Aceptado: 4/05/2007

\section{Formato de citación}

Saiz, Jesús; Fernández, Beatriz y Álvaro, José Luis (2007). De Moscovici a Jung: el arquetipo femenino y su iconografía. Athenea Digital, 11, 132-148. Disponible en http://psicologiasocial.uab.es/athenea/index.php/atheneaDigital/article/view/385/330.

Jesús Saiz. Jesús Saiz Galdós, Investigador Ramón Areces, Departamento de Psicología Social, Universidad Complutense de Madrid

Beatriz Fernández Ruiz. Profesora Contratada doctora. Sección departamental de Historia del Arte. Facultad de Bellas Artes. Universidad Complutense.

José Luis Álvaro. Catedrático de Psicología Social. Departamento de Psicología Social. Universidad Complutense.

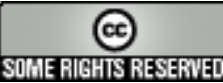

Este texto está protegido por una licencia Creative Commons.

Usted es libre de copiar, distribuir y comunicar públicamente la obra bajo las siguientes condiciones:

Reconocimiento: Debe reconocer y citar al autor original.

No comercial. No puede utilizar esta obra para fines comerciales.

Sin obras derivadas. No se puede alterar, transformar, o generar una obra derivada a partir de esta obra.

$\underline{\text { Resumen de licencia }}$

$\underline{\text { Texto completo de la licencia }}$ 